\title{
EMMPRIN/CD147 deficiency disturbs ameloblast-odontoblast cross-talk and delays enamel mineralization
}

Khaddam, Mayssam ; Huet, Eric ; Vallée, Benoît ; Bensidhoum, Morad ; Le-Denmat, Dominique ; Filatova, Anna ; Jimenez-Rojo, Lucia ; Ribes, Sandy ; Lorenz, Georg ; Morawietz, Maria ; Rochefort, Gael Y ; Kiesow, Andreas ; Mitsiadis, Thimios A ; Poliard, Anne ; Petzold, Matthias ; Gabison, Eric E ; Menashi, Suzanne ; Chaussain, Catherine

DOI: https://doi.org/10.1016/j.bone.2014.06.019

Posted at the Zurich Open Repository and Archive, University of Zurich ZORA URL: https://doi.org/10.5167/uzh-96932

Journal Article

Accepted Version

Originally published at:

Khaddam, Mayssam; Huet, Eric; Vallée, Benoît; Bensidhoum, Morad; Le-Denmat, Dominique; Filatova, Anna; Jimenez-Rojo, Lucia; Ribes, Sandy; Lorenz, Georg; Morawietz, Maria; Rochefort, Gael Y; Kiesow, Andreas; Mitsiadis, Thimios A; Poliard, Anne; Petzold, Matthias; Gabison, Eric E; Menashi, Suzanne; Chaussain, Catherine (2014). EMMPRIN/CD147 deficiency disturbs ameloblast-odontoblast cross-talk and delays enamel mineralization. Bone, 66:256-266.

DOI: https://doi.org/10.1016/j.bone.2014.06.019 


\section{Accepted Manuscript}

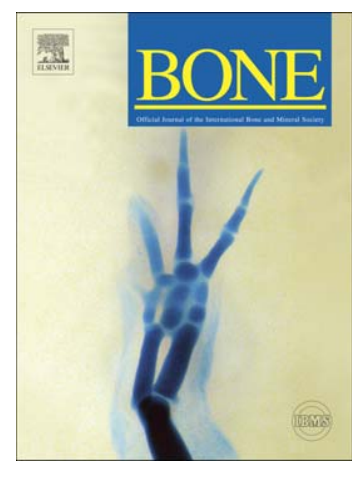

EMMPRIN/CD147 deficiency disturbs ameloblast-odontoblast cross-talk and delays enamel mineralization

Mayssam Khaddam, Eric Huet, Benoît Vallée, Morad Bensidhoum, Dominique Le-Denmat, Anna Filatova, Lucia Jimenez-Rojo, Sandy Ribes, Georg Lorenz, Maria Morawietz, Gael Y. Rochefort, Andreas Kiesow, Thimios A. Mitsiadis, Anne Poliard, Matthias Petzold, Eric E. Gabison, Suzanne Menashi, Catherine Chaussain

PII:

S8756-3282(14)00228-2

DOI: doi: 10.1016/j.bone.2014.06.019

Reference: BON 10392

To appear in: Bone

Received date: $\quad 20$ February 2014

Revised date: $\quad 10$ June 2014

Accepted date: 17 June 2014

Please cite this article as: Khaddam Mayssam, Huet Eric, Vallée Benoît, Bensidhoum Morad, Le-Denmat Dominique, Filatova Anna, Jimenez-Rojo Lucia, Ribes Sandy, Lorenz Georg, Morawietz Maria, Rochefort Gael Y., Kiesow Andreas, Mitsiadis Thimios A., Poliard Anne, Petzold Matthias, Gabison Eric E., Menashi Suzanne, Chaussain Catherine, EMMPRIN/CD147 deficiency disturbs ameloblast-odontoblast cross-talk and delays enamel mineralization, Bone (2014), doi: 10.1016/j.bone.2014.06.019

This is a PDF file of an unedited manuscript that has been accepted for publication. As a service to our customers we are providing this early version of the manuscript. The manuscript will undergo copyediting, typesetting, and review of the resulting proof before it is published in its final form. Please note that during the production process errors may be discovered which could affect the content, and all legal disclaimers that apply to the journal pertain. 
EMMPRIN/CD147 deficiency disturbs ameloblast-odontoblast cross-talk and delays enamel mineralization.

\section{Running Title: EMMPRIN and tooth formation}

Mayssam Khaddam ${ }^{*}$, Eric Huet ${ }^{2 *}$, Benoît Vallée ${ }^{2}$, Morad Bensidhoum ${ }^{4}$, Dominique Le-

Denmat $^{1}$, Anna Filatova ${ }^{5}$, Lucia Jimenez-Rojo ${ }^{5}$, Sandy Ribes ${ }^{1}$, Georg Lorenz ${ }^{6}$, Maria

Morawietz $^{6}$, Gael Y. Rochefort ${ }^{1}$, Andreas Kiesow ${ }^{6}$, Thimios A. Mitsiadis ${ }^{5}$, Anne Poliard ${ }^{1}$,

Matthias Petzold $^{6}$, Eric E. Gabison ${ }^{7}$, Suzanne Menashi $^{2}$ and Catherine Chaussain ${ }^{1,3}$

${ }^{1}$ EA 2496, Pathologies and Biotherapies of the Tooth, Dental school Universite Paris

Descartes Sorbonne Paris Cité, France. ${ }^{2}$ Laboratoire CRRET, Université Paris-Est, CNRS,

Créteil, France. ${ }^{3}$ AP-HP, Odontology Department, Groupement Hospitalier Nord Val de Seine

(Bretonneau, Louis Mourier), France. ${ }^{4}$ Laboratoire de Bioingénierie et Biomécanique OstéoArticulaire UMR CNRS 7052, Faculté de médecine Lariboisière St Louis Université Paris 7

Sorbonne Paris Cité, France. ${ }^{5}$ Department of Orofacial Development and Regeneration, Institute of Oral Biology, Center of Dental Medicine, Faculty of Medicine, University of Zurich, Switzerland. ${ }^{6}$ Fraunhofer Institute for Mechanics of Materials IWM Walter-HülseStr.Halle (Saale), Germany. ${ }^{7}$ Fondation ophtalmologique A de Rothschild, Université Paris Diderot, PRES Sorbonne Paris Cité, France

*These authors contributed equally to this work

Corresponding author: Catherine Chaussain. EA 2496, Dental School University Paris

Descartes, 1 rue Maurice Arnoux 92120 Montrouge, France. Tel: 33158076724. Fax:

33158076724. catherine.chaussain@ parisdescartes.fr

\section{"All authors state that they have no conflicts of interest."}




\section{ABSTRACT}

Tooth development is regulated by a series of reciprocal inductive signaling between the dental epithelium and mesenchyme, which culminates with the formation of dentin and enamel. EMMPRIN/CD147 is an Extracellular Matrix MetallopRoteinase (MMP) $\underline{\text { INducer }}$ that mediates epithelial-mesenchymal interactions in cancer and other pathological processes and is expressed in developing teeth. Here we used EMMPRIN knockout (KO) mice to determine the functional role of EMMPRIN on dental tissues formation. We report a delay in enamel deposition and formation that is clearly distinguishable in the growing incisor and associated with a significant reduction of MMP-3 and MMP-20 expression in tooth germs of KO mice. Insufficient basement membrane degradation is evidenced by a persistent laminin immunostaining, resulting in a delay of both odontoblast and ameloblast differentiation. Consequently, enamel volume and thickness are decreased in adult mutant teeth but enamel maturation and tooth morphology are normal, as shown by micro-computed tomographic (micro-CT), nanoindentation, and scanning electron microscope analyses. In addition, the dentino-enamel junction appears as a rough calcified layer of approximately $10 \pm 5 \mu \mathrm{m}$ thick (mean $\pm \mathrm{SD}$ ) in both molars and growing incisors of $\mathrm{KO}$ adult mice. These results indicate that EMMPRIN is involved in the epithelial-mesenchymal cross-talk during tooth development by regulating the expression of MMPs. The mild tooth phenotype observed in EMMPRIN KO mice suggests that the direct effect of EMMPRIN may be limited to a short time window, comprised between basement membrane degradation allowing direct cell contact and calcified matrix deposition.

KEY WORDS: TOOTH FORMATION, MMPS, CELL INTERACTION, ENAMEL PROTEINS 


\section{INTRODUCTION}

Tooth development results from reciprocal inductive interactions between the ectomesenchyme and oral epithelium and proceeds through a series of well-defined stages including the initiation, bud, cap and bell stages [1-6]. At the bell stage which is the last step of tooth crown formation., signals from the dental epithelium (i.e., inner enamel epithelium) instruct dental mesenchymal cells to differentiate into odontoblasts. Differentiated odontoblasts signal back to inner enamel epithelial cells and induce their differentiation into ameloblasts, which are responsible for enamel matrix synthesis. Ameloblast terminal differentiation necessitates the presence of an extracellular matrix that is secreted by odontoblasts and forms the predentin [7]. The degradation of the basement membrane (BM) separating the dental epithelium from the mesenchyme is a key step in this process that allows direct contact of ameloblasts with both odontoblasts and the unmineralized dentin matrix [3, 8]. Matrix metalloproteinases (MMPs) are involved in all stages of tooth formation [9-11]. At the bell stage, MMPs have a major role in BM degradation $[12,13]$, thus allowing direct cross-talk between odontoblasts and ameloblasts [12-14]. It has been shown that at more advanced stages MMPs also regulate the processing of dental extracellular matrix (ECM) proteins prior to mineralization. Indeed, it has been demonstrated that MMPs regulate amelogenin (AMEL) cleavage by enamelysin (MMP-20) during early enamel maturation [9, $15-20]$.

The notion of direct epithelial-mesenchymal (or epithelio-stromal) interactions was first introduced in the cancer field when EMMPRIN, a membrane glycoprotein also known as CD147, was identified as a MMP inducer present at the cell surface of tumor cells which can 
activate stromal cells through direct contact and signal them to increase MMP production [21]. Recently accumulating data also advocate a role for EMMPRIN in modulating MMP expression during non-tumorigenic pathological conditions as well as in physiological situations such as tissue remodeling and cytodifferentiation events [22-29]. For example, the presence of EMMPRIN in tissues affected by rheumatoid arthritis indicates that it is also involved in bone and cartilage deterioration [30-32]. Furthermore, it has been suggested that EMMPRIN plays a role in cell differentiation, polarity and survival [33]. Knockout (KO) mice have been generated to analyze the functional significance of EMMPRIN during development and adulthood [34]. These mice exhibited several developmental defects, are smaller than wild-type (WT) mice and are usually unable to undergo implantation. The EMMPRIN mutant offspring are sterile, thus demonstrating deficiencies in spermatogenesis and fertilization. In addition, these null mice are blind due to defective retinal development and have faulty sensory and memory functions [34-36].

The expression of EMMPRIN in the developing tooth germs was previously described [37, 38]. EMMPRIN expression was shown to increase gradually in the forming molar germ in mice from E14 to P1 [38]. Expression was also reported in tooth germs of rats at the bell stage, in the enamel organ on the cell membranes of ameloblasts and in the stratum intermedium, as well as in the mesenchyme at the distal ends of differentiating odontoblasts (37). Using ex-vivo culture of E11 mice mandibles treated with EMMPRIN siRNA, Xie et al. have proposed that EMMPRIN may be involved in tooth morphogenesis [38]. However, the in vivo role of EMMPRIN in tooth development and homeostasis is still unknown. In this study, our objective was to investigate the EMMPRIN functions in tooth formation using EMMPRIN KO mice by exploring the modifications occurring in their dental phenotype and the consequences on EMMPRIN's molecular targets, in particular on MMPs. The expression of the gelatinases (MMP-2 and MMP-9), stromelysin-1 (MMP-3), and enamelysin (MMP-20) 
was more particularly investigated as well as their possible role in basement membrane degradation and early enamel maturation, two critical steps for normal tooth formation where MMP activity has been shown to be important $[12,13,39,40]$. Our results suggest a role for EMMPRIN in epithelial-mesenchymal interactions by regulating expression of specific MMPs.

\section{MATERIAL AND METHODS}

\section{Animals}

EMMPRIN mice were a kind gift from Dr.Takashi Muramatsu, Department of Biochemistry, Nagoya University School of Medicine, Japan [34]. Heterozygous breeding was carried out and tail snips were collected for genotyping. DNA was extracted from the snips using DNeasy Blood and Tissue Kit (Qiagen, France) and the genotype was determined by PCR using primers for EMMPRIN and Neomycin resistance genes [34]. Offspring with the EMMPRIN gene null mutant $(\mathrm{KO})$ phenotype were maintained under the same conditions as those for the wild type (WT) mice. Post-natal littermate WT (+/+) and KO (-/-) mice at day 1, day 5, 3 and 18 months were examined in this study. The protocol was approved by the Animal Care Committee of French Veterinary Services (DDSV Val de Marne, France).

\section{Immunohistochemistry}

The heads of post-natal day $1 \mathrm{WT}$ and KO mice were fixed overnight in a $4 \%$ paraformaldehyde solution (6 mice per group). The samples were progressively dehydrated and embedded in Paraplast (Oxford Labware, St Louis, MO, USA). Seven-micrometer-thick tissue sections were prepared, deparaffined and rehydrated. Endogenous peroxidases were blocked in $0.4 \%$ hydrogen peroxide in methanol. After extended rinsing in PBS, background 
activity was blocked at room temperature for 90 min in $1 \%$ bovine serum albumin (BSA) in PBS. Goat polyclonal EMMPRIN antibody (Santa Cruz, Heidelberg, Germany), rabbit monoclonal MMP-20 antibody (Abcam, Cambridge, UK), rabbit polyclonal laminin antibody (Sigma-Aldrich, Saint-Louis, MO) and rabbit polyclonal amelogenin antibody (kind gift to EA2496 from Dr. Carolyn W. Gibson, Department of Anatomy and Cell Biology, University of Pennsylvania School of Dental Medicine, Philadelphia, PA) were used at 1/400, 1/100, 1/100 and 1/150 dilution, respectively. Sections were treated overnight in a moist chamber at $4^{\circ} \mathrm{C}$ and further incubated for $90 \mathrm{~min}$ with a polyclonal swine anti-rabbit immunoglobulin-G peroxidase-conjugated or a polyclonal rabbit anti-Goat immunoglobulin-G peroxidaseconjugated (Dako, Glostrup, Denmark), as secondary antibody. Peroxidase labeling was revealed ( 1 to $10 \mathrm{~min}$ according to the antibody) in a dark chamber using 3-3 diaminobenzidine tetrahydrochloride (Sigma-Aldrich) with hydrogen peroxide in Phosphate Buffered Saline solution (PBS). To exclude nonspecific binding, controls were carried out by omitting the primary antibody. For laminin, a goat anti-rabbit immunoglobulin-G Alexa Fluor 488 was used at 1/ 200 (Sigma-Aldrich) in a dark-chamber and nuclei were stained with DAPI solution at 1/ 4000 (Invitrogen, Life technologies, Carlsbad, CA) for 3 min. Images were merged using Image $\mathrm{J}$ software (NIH, Bethesda, MD).

\section{Total protein extraction from tooth germs}

Maxillary and mandibular molar germs (M1 + M2) were dissected from 5 day-old post-natal WT and KO mice ( $n=6$ mice per group). Tooth germs were mixed and ground to a fine powder in presence of liquid nitrogen, then homogenized in ice-cold extraction buffer (10 germs in $200 \mu \mathrm{L}$ buffer: $50 \mathrm{mM}$ Tris-HCl, $\mathrm{pH} 7.5$, containing $5 \mathrm{mM}$ EDTA, $0.9 \% \mathrm{NaCl}$ and $0.2 \%$ Triton X-100), supplemented with 1/100 Protease Inhibitor Cocktail Set V EDTA free (Calbiochem, La Jolla, CA) [9]. The resulting homogenates were then briefly sonicated on ice 
( 3 times $5 \mathrm{sec}$ ), cleared by centrifugation at $10,000 \mathrm{~g}$ for $15 \mathrm{~min}$ at $4{ }^{\circ} \mathrm{C}$ and stored at $-80^{\circ} \mathrm{C}$. Same procedure was carried out with the soft part of the growing lower incisor from 3 monthold mice.

\section{MMP activity measurement}

MMP activity was measured using the generic-fluorescent quenched substrate Mca-PLGL(Dpa)-AR-NH2 (R\&D System, Minneapolis, MN). Briefly, one microgram of each tooth germ extract was incubated with $2 \mu \mathrm{M}$ Mca-PLGL-(Dpa)-AR- $\mathrm{NH}_{2}$ in a $50 \mathrm{mM}$ Tris- $\mathrm{HCl}$ buffer, pH 7.5, containing $150 \mathrm{mM} \mathrm{NaCl}, 5 \mathrm{mM} \mathrm{CaCl}_{2}$ and $0.05 \%$ Brij 35. The reaction was allowed to proceed overnight at $22{ }^{\circ} \mathrm{C}$ and then was stopped by adding $10 \mathrm{mM}$ EDTA. The rate of substrate cleavage was measured in triplicate for each extract using a Tecan Infinite $®$ M1000 spectrofluorometer with excitation and emission wavelengths of 326 and $393 \mathrm{~nm}$, respectively. Less than $5 \%$ of the substrate was hydrolyzed during the rate measurements.

\section{Zymographic analysis}

Protein homogenates were analyzed by gelatin zymography to identify MMP-2 and MMP-9 isoforms. Electrophoresis was carried out using a miniprotean II system (BIO-RAD, Hercules, CA) on $8 \%$ polyacrylamide gels containing $1 \mathrm{mg} / \mathrm{mL}$ gelatin. Samples $(3 \mu \mathrm{g})$ were halfdiluted in $1 \mathrm{M}$ Tris, pH 6.8, containing $50 \%$ glycerol and $0.4 \%$ bromophenol blue, and gels were run under Laemmli conditions. Following electrophoresis gels were washed twice (30 min each) in $200 \mathrm{ml} \mathrm{2.5 \%} \mathrm{Triton} \mathrm{X-100} \mathrm{under} \mathrm{constant} \mathrm{mechanical} \mathrm{stirring} \mathrm{and} \mathrm{incubated} \mathrm{in}$ $50 \mathrm{mM}$ Tris- $\mathrm{HCl}$ buffer, $\mathrm{pH} 7.5$, containing $150 \mathrm{mM} \mathrm{NaCl}, 5 \mathrm{mM} \mathrm{CaCl}_{2}$ and $0.05 \%$ Brij 35, for $24 \mathrm{~h}$ at $37^{\circ} \mathrm{C}$. Gels were stained with $0.25 \%$ Coomassie brilliant blue G-250 (50\% methanol, $10 \%$ acetic acid) and destained appropriately (40\% methanol, $10 \%$ acetic acid). Proteinase activity was evidenced as cleared (white) bands. Bands were digitalized and 
compared using image $\mathbf{J}$ software. Homogenates were also analyzed by casein zymography to identify MMP-20 and MMP-3. Zymograms were run on Novex 4-16\% casein zymogels (Life Technologies, Carlsbad, CA), incubated at $37^{\circ} \mathrm{C}$ for $48 \mathrm{~h}$ in $50 \mathrm{mM}$ Tris- $\mathrm{HCl}$ buffer, $\mathrm{pH} 7.5$, containing $5 \mathrm{mM} \mathrm{CaCl}_{2}$ to allow MMP activity). To detect KLK-4, casein zymograms were run in the same conditions excepted that $20 \mathrm{mM}$ EDTA were added to the incubation buffer to inhibit MMP activity (adapted from [40]). For casein zymograms, recombinant MMP-3 (R\&D system) and MMP-20 (kind gift from Pr Pamela K. DenBesten, UCSF, CA) were loaded as positive control.

\section{Western blot analysis}

Protein homogenates $(20 \mu \mathrm{g})$ were subjected to SDS-PAGE on 4-20\% precast gels (MiniPROTEAN TGX Precast Gels, BIO-RAD) and transferred onto a nitrocellulose membrane (BIO-RAD). Membranes were incubated with anti-amelogenin (1/750), anti-enamelin (1/500, Santa Cruz), anti-ameloblastin (1/1000, R\&D system), anti-EMMPRIN (1/1000), anti-MM-20 (1/1000, N-terminal MMP-20 antibody, Sigma, Saint Louis, MO), anti-KLK4 (1/500, Santa Cruz), or anti-MMP-3 (1/700; Abcam) antibodies overnight at $4{ }^{\circ} \mathrm{C}$. The membranes were incubated with a 1/1000 dilution of a peroxidase-linked anti-rabbit IgG (amelogenin, MMP-3 and -20, KLK4) or anti-goat (EMMPRIN, enamelin and ameloblastin) secondary antibody for 1 hour at room temperature and developed by means of BM Chemiluminescence Western Blotting Kit (Roche Diagnostics, Meylan, France). As a control for protein loading, the membranes were carefully washed and stripped with stripping buffer (Pierce Chemical, Rockford, IL) and processed with a rabbit monoclonal anti-GAPDH antibody (EPITOMICS, California, USA). The relative intensity of bands was digitalized and quantified using image $\mathbf{J}$ software. 


\section{Micro-X-ray computed tomography (Micro-CT) analysis}

For exploration of potential mineral part of tooth alterations in adult mice, 3 and 18 month-old mandibles (6 mice per group) were fixed for $48 \mathrm{~h}$ in $4 \%$ paraformaldehyde and stored in $70 \%$ ethanol at $4^{\circ} \mathrm{C}$. Half mandibles were subjected to a desktop micro-CT, (Skyscan 1172, Skyscan, Aartselaar, Belgium). The micro-CT settings were used as follows: $9 \mu \mathrm{m}$ resolution, voltage $80 \mathrm{kV}$; current $100 \mu \mathrm{A}$; exposure time $400 \mathrm{~ms}$; $180^{\circ}$ rotation; rotation step 0.4 degree; frame averaging 4 . The scanning time was approximately 4 hours/sample. A total of 1700 native slice frames per sample were reconstructed using NRecon software (Skyscan, Belgium). Total mineralized tissue volume (80-255 grayscale units) was compared to enamel volume using this software. The lower and upper thresholds for enamel were defined to be from 181-255 grayscale units, while the thresholds for bone and dentin were defined as 80 180 grayscale units on an 8-bit grayscale. Same values were used for all samples analyzed. The dicom data frames were subsequently analyzed using OsiriX imaging software (3.7.1 version). The scans resulted in reconstructed 3-D data sets with a voxel-size of $9.92 \mu \mathrm{m}$. Enamel thickness was measured in M1, M2, incisor under M1, and incisor under M2 from $\mu \mathrm{CT}$ images using CTAn software (Skyscan, Belgium) following a previously described method [41].

\section{Nanoindentation}

Cross -section samples of molars and incisors were prepared by cutting the resin-embedded samples perpendicular to the sagittal axis of the jaw, at the level of the mesial cusp of the first molar. In order to achieve an appropriate flatness and surface quality for the nanoindentation experiments, all surfaces of the cross-sections were grinded using a Presi Mecapol P230 polishing machine. For the grinding procedure SiC paper was applied starting with mesh size of 120 , which was subsequently decreased to 4000. After cleaning, the nanoindentation 
measurements were performed using a G200 Nanoindenter (Agilent Technologies, Inc., Vista, CA, USA) equipped with a Berkovich-shaped diamond indenter tip. Samples were tested in dry condition. For all nanoindentation measurements, the displacement-controlled continuous stiffness mode (csm) technique was applied. In this mode, small oscillations of the indenter tip are superposed to the overall indenter displacement of the loading and unloading testing cycle [42]. Using the csm mode allows determining material parameters such as hardness and Young's modulus values as a function of depth for the complete range of indentation. For the experiments a maximum indentation depth of $3000 \mathrm{~nm}$ was chosen while the loading speed was set to result in a strain rate (averaged within the locally loaded sample region) of $0.05 \mathrm{1} / \mathrm{s}$. Typically, 15 single indentation tests were performed for each of the specimen regions to be investigated ( $\mathrm{e}$ - enamel; dfp - dentin far from pulp; dmr - dentin middle region; $\mathrm{cf}$. the light microscopic image in Fig.4C). A representative indentation depth of $500 \mathrm{~nm}$ was chosen for determining the nanoindentation data on hardness and Young's modulus. This value was found well suitable to compare all different enamel and dentine samples while minimizing effects resulting from surface microstructure. The measured modulus and hardness data are in close agreement with the values found in similar nanoindentation studies of mice molars [43, 44] determined at comparable indentation depths.

\section{SEM analysis}

Mandibles of the 3 month-old mice were prepared for SEM analysis. Cross-sections at the level of the mesial cusp of the first molar were performed with a saw equipped with a diamond disk (Struers, Champigny sur Marne, France) under a continuous water spray. After thorough polishing, surfaces were cleaned with 5\% sodium hypochlorite for 2 min, rinsed twice with distilled water, etched with $2 \%$ Nitric acid for $10 \mathrm{~s}$, and then thoroughly rinsed with distilled water. Carbon or gold sputter-coated surfaces were observed under a scanning 
electron microscope (Cambridge S260 SEM, UK), equipped with an Everhart-Thornley and BSE electron detector, and EDX spectrometer for X-ray microanalysis (BRUKER AXS, France) with Esprit2 software.

\section{RT-PCR analysis for gene expression}

Gene expression was analyzed after extraction of total RNA from the latest $2 \mathrm{~mm}$ of mandibular incisor root (soft part) of 3-month-old EMMPRIN $-/$ - and $+/+$ mice $(n=6$ mice per group), using Mini RNA Isolation kit (GE Healthcare, Little Chalfont, United Kingdom). The integrity of RNA was controlled with a Bioanalyzer (Agilent Bioanalyzer), purity checking and RNA dosage were carried out with a nanodrop (Nanovue Plus, GE Healthcare Life Sciences, UK). $250 \mathrm{ng}$ of total RNA was reverse-transcribed with (cDNA kit VersoTM, ThermoFicher, Waltham, MA). For semi-quantitative RT-PCR, cDNA was amplified with specific primer (Go Tag®Hot Start polymerase, Promega, Fitchburg, WI). MMP-2, $M M P-3$, $M M P-9, M M P-20, E M M P R I N$, and $K L K-4$, cDNA expression were compared to GAPGH expression (Supplementary Table 1).

For quantitative real-time PCR (qRT-PCR) analysis, cDNA was amplified with specific primers (Eurofins mwg operon, Ebersberg, Germany) in a Light cycler ${ }^{\circledR} 480$ SYBR Green I Master (Roche, Penzberg, Upper Bavaria, Germany). Each primer pair was chosen for best efficiency and controlled for specificity (Table 1). qRT-PCR analysis was carried out using LigthCycler 480 [45]. The PCR cycles consisted of an initial pre-incubation step $\left(95^{\circ} \mathrm{C}\right.$ for 5 $\mathrm{min})$, followed by 45 cycles of amplification $\left(95^{\circ} \mathrm{C}\right.$ for $5 \mathrm{~s}, 55^{\circ} \mathrm{C}$ for $5 \mathrm{~s}, 70^{\circ} \mathrm{C}$ for $\left.10 \mathrm{~s}\right)$. Relative gene expression levels were estimated using the deltaCq method [46]. GAPDH and ubiquitine $C(U B C)$ were determined using GeNorm software on a set of 5 standard housekeeping genes and were used as housekeeping genes for the rest of the study. Results were expressed as mean $\pm \mathrm{SD}$ of relative mRNA level for EMMPRIN -/- and +/+ mice. 


\section{Isolation and culture of ED18 tooth germs}

C57B6 wild type mice were mated overnight and the detection of the vaginal plug was counted as day 0 (ED0). Embryos were collected from one pregnant mouse at day 18 (E18) and the mandibular first molar extracted from hemi-mandible under a stereoscopic microscope. The tooth germ was then cultured on a semi-solid medium made of DMEM/F12 containing $20 \%$ fetal calf serum (FCS) supplemented with ascorbic acid $(0.18 \mathrm{mg} / \mathrm{ml})$, Lglutamine $(2 \mathrm{mM})$, penicillin/streptomycin $(50$ units $/ \mathrm{ml})$ and agar $(0.36 \%)$ [47]. Cultures were incubated at $37^{\circ} \mathrm{C}$ in a humidified atmosphere of $5 \% \mathrm{CO} 2$.

\section{Small interfering RNA transfection (siRNA)}

Knockdown of EMMPRIN expression was performed on molar tooth germs by siRNA treatment one day after the beginning of the culture. Two different siRNA oligos, siEMMPRIN (Ambion, siRNA ID: 10372- siRNA ID: s2098, Applied Biosystems) or scramble siRNA oligos (BLOCK-iT fluorescent oligo, Invitrogen), siScramble, were transfected in the cultured germ in the absence of FCS and antibiotics. Briefly, siRNA were first diluted in Opti-MEM medium before an incubation of $15 \mathrm{~min}$ with the mix of Lipofectamine RNAiMAX transfection reagent previously diluted in Opti-MEM (Invitrogen). Each siRNA was added on the cultured germ at the final concentrations of 60 and $120 \mathrm{nM}$. After $48 \mathrm{~h}$ of incubation, transfection medium was removed and germs were treated for RNA extraction. This experiment was repeated in three independent experiments.

\section{Statistical analysis}

Values are presented as means \pm SD with at least 6 samples ( 6 germs or 6 animals) per group. The normality of the distribution was tested with the Shapiro-Wilk test and the homogeneity 
of variance was tested with the F-test. When the distribution of the data for each group respected the normal law and the variance of both groups were homogeneous, T-test for nonpaired measures was used. When the distribution of at least one of the groups did not follow the normal law, the U-Mann Whitney test was applied. The critical p-value for statistical significance was $\mathrm{p}=0.05$.

\section{RESULTS}

\section{Tooth phenotype in EMMPRIN KO mice.}

Tooth phenotype was examined on post-natal day 1 mandible in first (M1) and second (M2) molars (Fig.1 Panel A). At this time point, the first molar (M1) germ is at the late bell stage characterized by terminal odontoblast and ameloloblast differentiation. The second molar (M2) germ is at early bell stage characterized by last cell mitosis [8] and basement membrane degradation allowing for terminal cell differentiation. When examined microscopically, the morphology of the developing molar germs of WT and EMMPRIN KO mice appeared similar with well-visible formed tooth crowns (Fig.1 Panel A). EMMPRIN immunohistochemical analysis confirmed the absence of EMMPRIN expression in KO mice. In WT, EMMPRIN expression was seen in both ameloblasts and odontoblasts, depending on the development stage (Fig.1, Panel A). Such observations, including morphology and EMMPRIN expression were also made on sagittal sections of the developing incisor in 3-month-old mice, which as a continuously growing tooth, recapitulates all the developmental stages (Fig.1, Panel B, supplementary fig. 1).

Micro-CT analysis of mandibles from 3 month-old mice showed no evident difference between molars but a delay in mineralization of the continuously growing incisor in EMMPRIN KO mice (Fig.2A). In WT mice, incisor mineralization was observed underneath M3, whereas mineralization was only visible at the level of M2 in KO mice. Quantitative 
analysis of reconstructed mandible samples demonstrated a significant lower enamel volume in EMMPRIN KO mice when compared to WT mice, $6.94 .10^{8} \mu \mathrm{m}^{3}$ versus $10.85 .10^{8} \mu \mathrm{m}^{3}$, respectively (Fig.2B). Similar mineralization delay of the continuous growing incisor was observed in 18 month-old mice (data not shown). Enamel thickness, measured at M1, M2, incisor under M1, and incisor under M2 from Micro-CT images, was significantly lower in EMMPRIN KO mice compared to WT $(0.139 \pm 0.006$ versus $0.117 \pm 0.006 \mathrm{~mm}$ at $\mathrm{M} 1, \mathrm{p}<$ $0.05 ; 0.140 \pm 0.003$ versus $0.124 \pm 0.001 \mathrm{~mm}$ at incisor under $\mathrm{M} 1, \mathrm{p}<0.001 ; 0.148 \pm 0.007$ versus $0.112 \pm 0.006 \mathrm{~mm}$ at $\mathrm{M} 2, \mathrm{p}<0.01$, and $0.142 \pm 0.002$ versus $0.127 \pm 0.002 \mathrm{~mm}$ at incisor under M2, $\mathrm{p}<0.01$; respectively) (Fig.2B).

To assess the quality of enamel and dentin associated with EMMPRIN deficiency, we then performed nanoindentation on 3 month- old samples in frontal sections performed at the level of M1 (Fig.2C). No significant change of the enamel hardness and elasticity (Young's modulus) was observed between $\mathrm{KO}$ and WT mice both in M1 and in the underlying growing incisor. Furthermore, dentin analysis by nanoindentation showed no significant modification either in the outer or in the deeper dentin layer.

\section{Lower MMP activity in the tooth germs of EMMPRIN deficient mice}

Molar and incisor germ extracts were analyzed for total MMP activity using a broad ranged fluorescent substrate for MMPs (Fig.3A). A decrease of $25 \%$ in activity was observed in the extracts of EMMPRIN KO mice when compared with WT mice. MMP-3 expression was shown to be about $70 \%$ lower in KO mice by both RT-PCR and immunoblot (Fig.3B). Lower MMP-3 activity in KO was detected by casein zymography (Fig.3B). In contrast, analysis of the transcript and protein levels of MMP-2 and MMP-9 showed no detectable difference between WT and KO animals (Fig.3C-D). MMP-20 expression was significantly lower in KO mice at both the transcript and protein levels (Fig.4A), and fainter MMP-20 activity was 
observed by casein zymography (Fig.4A). The decrease in MMP-20 expression was confirmed by immunostaining in the M1 germ (Fig.4C, a-d). In WT mice, MMP-20 staining was associated with the matrix at the interface with the secreting pole of ameloblasts. Staining increased progressively from the less differentiated cells located in the intercuspal curve (Fig.4C a), reaching maximal intensity at the tip of the cusps where the cells are fully differentiated (Fig.4C c). By contrast, in $\mathrm{KO}$ mice, only weak staining could be discerned in the neo-formed matrix at the tip of the cusps. We then sought to determine whether the decrease in MMP-20 was associated with a modification in enamel matrix protein cleavage. AMEL immunostaining in the M1 germ was localized mainly at the secreting pole of the ameloblasts, particularly intense at the tip of the cusps which corresponds to the start of enamel synthesis but there was no notable difference between WT and KO mice (Fig.4C,e-h). In addition, a normal profile of the protein expression was shown in the Western blot analysis of tooth germ extracts (Fig.4B). Similar results were obtained by Western blot analysis for the expression of enamelin (Fig.4B). Regarding ameloblastin expression, several bands were detected from 65 to $17 \mathrm{kDa}$, some of the intermediate bands being slightly less detectable in KO. The analysis of the transcripts of Kallicrein-4 (KLK-4), an enzyme involved in late enamel maturation [16], showed a significantly higher level of expression in KO mice, which however could not be detected at the protein level by either western blot (data not shown) or casein zymographic analysis (Supplementary fig.2).

\section{EMMPRIN regulates the expression of several MMPs in tooth germ cultures.}

To further assess the direct role of EMMPRIN on MMP expression, we investigated the effects of EMMPRIN inhibition on tooth germs in culture [48]. In that purpose, molar germs sampled at E18 were cultured on semi-solid culture medium for 1 day prior to inhibition by siRNA. The germs were then treated for $48 \mathrm{~h}$ with two different concentrations of EMMPRIN 
siRNA (Fig.5). RT-PCR analysis showed that EMMPRIN expression was notably diminished at both siRNA concentrations (63\% and $90 \%$, respectively). This decrease had no detectable effect on the expression of MMP-2, while a significant decrease of MMP-3 (50\% and $65 \%$, respectively) and MMP-20 (about $80 \%$ for both siRNA concentrations) expression was observed. In addition, a $20 \%$ decrease was also observed with the highest siRNA concentration for MMP-9.

\section{Delayed basement membrane degradation in the molar germs of EMMPRIN deficient} mice

As the expression of MMP-3 is lowered in EMMPRIN KO mice and when EMMPRIN is silenced by siRNA, we explored the degradation of the basement membrane at early bell stage by fluorescent immunolabeling of laminin, one of its major components (Fig.6A). Laminin immunostaining appeared continuous in EMMPRIN KO mice while it was faint and discontinuous in the WT, suggesting delayed basement degradation in the absence of EMMPRIN. In order to assess the consequences of this delayed degradation in the adult mice, scanning electron microscopy (SEM) analysis of sections of 3 month-old mandibles was performed at the level of M1. Results revealed that whereas both dentin and enamel appeared to retain their normal structure in EMMPRIN KO mice (supplementary fig.3), clear differences could be discerned at the dentino-enamel junction (DEJ), the boundary between these two anatomical structures, in molars (Fig.6B C,D) and developing incisor (Fig.6B A,B). While the DEJ in WT mice appeared as a well-intricate structure providing a solid anchorage of enamel within dentin, it consisted of a rough calcified layer of approximately $10 \pm 5 \mu \mathrm{m}$ (mean $\pm \mathrm{SD}$ ) in the $\mathrm{KO}$ mice. 


\section{DISCUSSION}

EMMPRIN/CD147 is a MMP inducer considered as an important mediator of epithelio-stromal interactions in several normal and pathological processes [22]. EMMPRIN is known to be expressed during rodent tooth formation $[37,38]$, and data obtained from exvivo germ culture have suggested that it was involved in tooth morphogenesis [38]. However, the precise in vivo function of this molecule in dental tissues remained to be elucidated. This study shows that EMMPRIN KO adult mice, although globally displaying a normal tooth morphology, present several dental alterations including decreased enamel volume and thickness, likely resulting from a downstream action of EMMPRIN on MMPs. Indeed, we showed that the expression and activity of MMP-3, which is able to degrade basement membrane components [49], and MMP-20 that is necessary for enamel formation [16], are down-regulated in teeth of EMMPRIN KO mice, as well as upon EMMPRIN siRNA inhibition

The proteolytic disruption of the basement membrane during tooth development is a key step that promotes tissue remodeling through the modification of the epithelialmesenchymal interactions [8]. This disintegration allows a direct interaction between these two tissues necessary for terminal cell differentiation. Here we demonstrate that EMMPRIN, via regulation of MMP expression, is involved in the disruption of the anatomical barrier that separates dental epithelium from mesenchyme. The direct cell-to-cell contact allowed by basement membrane degradation was delayed in teeth of EMMPRIN KO mice, as suggested by the persisting laminin immunostaining. This is consistent with the inhibition of MMP-3 which is known to be involved in the basement membrane degradation [49]. Consequently, an enamel mineralization delay was observed in the growing incisors of all the explored 
EMMPRIN KO mice. Although technically difficult to confirm, it is expected that molar germs also display enamel mineralization delay. This assumption is strengthened by the delay observed in basement membrane degradation in the molar germs, and by the defects observed at the DEJ in both adult molars and incisors.

Our results show that EMMPRIN is intensely expressed in epithelial cells (i.e. preameloblasts and stratum intermedium) of developing teeth prior dentin and enamel formation. These data confirm previous findings showing increasing expression of EMMPRIN from the bud to the bell stage in stratum intermedium and inner dental epithelium layers [37, 38]. However, at more advanced developmental stages (start of dentin and enamel deposition), we demonstrate that EMMPRIN protein is also expressed by odontoblasts. This rapid switch suggests an involvement of EMMPRIN in the well-tuned epithelia-mesenchymal dialogue that allows tooth development.

MMP-20 production was also decreased in dental tissues of EMMPRIN KO mice. MMP-20, which is a tooth-specific enzyme [18], is implicated in the early stages of enamel maturation and proposed to be solely responsible for AMEL processing during the secretory stage [17]. At this early stage of enamel maturation, MMP-20 has also been shown to be responsible of the cleavage of enamelin and ameloblastin, two other enamel matrix proteins $[39,40]$. However, the decreased MMP-20 expression observed in the teeth of the EMMPRIN KO mice were solely associated with decreased enamel volume and thickness, which did not match the severe enamel abnormalities observed in teeth of the MMP-20 KO mice [50-52]. In addition, the nanoindentation study did not reveal any differences between EMMPRIN KO and WT mice, suggesting a rather normal enamel mineralization. This contrasts the tooth phenotype observed in the MMP-20 KO mice [53]. Indeed, MMP-20 KO mice exhibit a severe tooth phenotype with altered rod pattern and hypoplastic enamel that delaminates from the dentin $[51,54]$. This abnormal phenotype was suggested to result from the lack of MMP- 
20-dependent AMEL cleavage, highlighting the importance of enamel matrix proteolysis for proper enamel formation. Normal enamel mineralization in teeth of EMMPRIN KO mice may be explained by the fact that MMP-20, although markedly decreased, may still be sufficient to cleave enamel matrix proteins during early enamel maturation.

Interestingly, expression and activity of MMP-2 and MMP-9, which are regulated by EMMPRIN in several tissues and various pathological and repair conditions such as tumor invasion and corneal wound healing [23, 28, 32], remained normal in dental tissues of EMMPRIN KO mice. This highlights a complex mechanism of MMP regulation by EMMPRIN, which depends on the tissue context. Altogether, the mild consequences of the absence of EMMPRIN on the adult tooth phenotype, in spite of the lower expression of both MMP-3 and MMP-20, may indicate that the level of MMP expressed in the developing tooth germs in EMMPRIN KO mice is sufficient to allow for a correct tooth development, although the existence of a compensatory mechanism implicating other proteases cannot be excluded. In addition, the direct effect of EMMPRIN on the epithelia-stromal interaction may be limited since it is only allowed during a short time window, namely between basement membrane degradation allowing direct cell contact and before calcified matrix deposition which constitutes cell barriers, hence limiting EMMPRIN's scope of action (Figure 7).

In conclusion, our study suggests that EMMPRIN, through the induction of proteases, may orchestrate the epithelial-mesenchymal cross-talk necessary for tooth formation, by enabling cleavage of the basement membrane and thus direct cell-cell interactions. At more advanced stages, EMMPRIN can also facilitate enamel maturation by inducing proteases such as MMP-20 that are capable of cleaving matrix components.

\section{Acknowledgements}


The authors thank Dominique Septier (EA2496, University Paris Descartes, France) for her great assistance with tooth germ histology, and Julie Lesieur (EA2496, University Paris Descartes, France) for her help with molecular biology experiments. This work was supported by grants from University Paris Descartes, the grant IDEX Sorbonne Paris Cité “Once upon a tooth", grants from "la Fondation pour la recherché médicale" (FRM) for EA2496, and University Paris-Est Créteil. Parts of this study (nanoindentation) were financially supported by the Investitionsbank Sachsen-Anhalt, Germany (ZWB 1304/00006).

\section{REFERENCES:}

[1] Ruch JV, Karcher-Djuricic V, Gerber R. [Determinants of morphogenesis and cytodifferentiations of dental anloges in mice]. Journal de biologie buccale 1973;1: 45-56.

[2] Slavkin HC. Embryonic tooth formation. A tool for developmental biology. Oral sciences reviews 1974;4: 7-136.

[3] Caton J, Tucker AS. Current knowledge of tooth development: patterning and mineralization of the murine dentition. J Anat 2009;214: 502-15.

[4] Miletich I, Sharpe PT. Normal and abnormal dental development. Human molecular genetics 2003;12 Spec No 1: R69-73.

[5] Thesleff I, Hurmerinta K. Tissue interactions in tooth development. Differentiation; research in biological diversity 1981;18: 75-88.

[6] Mitsiadis TA, Luder HU. Genetic basis for tooth malformations: from mice to men and back again. Clin Genet 2011;80: 319-29.

[7] Zeichner-David M, Diekwisch T, Fincham A, Lau E, MacDougall M, Moradian-Oldak J, Simmer J, Snead M, Slavkin HC. Control of ameloblast differentiation. Int J Dev Biol 1995;39: 69-92.

[8] Olive M, Ruch JV. Does the basement membrane control the mitotic activity of the inner dental epithelium of the embryonic mouse first lower molar. Developmental biology 1982;93: 301-7.

[9] Bourd-Boittin K, Fridman R, Fanchon S, Septier D, Goldberg M, Menashi S. Matrix metalloproteinase inhibition impairs the processing, formation and mineralization of dental tissues during mouse molar development. Exp Cell Res 2005;304: 493-505.

[10] Fanchon S, Bourd K, Septier D, Everts V, Beertsen W, Menashi S, Goldberg M. Involvement of matrix metalloproteinases in the onset of dentin mineralization. Eur J Oral Sci 2004;112: 171-6.

[11] Chaussain-Miller C, Fioretti F, Goldberg M, Menashi S. The role of matrix metalloproteinases (MMPs) in human caries. J Dent Res 2006;85: 22-32.

[12] Heikinheimo K, Salo T. Expression of basement membrane type IV collagen and type IV collagenases (MMP-2 and MMP-9) in human fetal teeth. J Dent Res 1995;74: 1226-34.

[13] Sahlberg C, Reponen P, Tryggvason K, Thesleff I. Association between the expression of murine $72 \mathrm{kDa}$ type IV collagenase by odontoblasts and basement membrane degradation during mouse tooth development. Arch Oral Biol 1992;37: 1021-30. 
[14] Sahlberg C, Reponen P, Tryggvason K, Thesleff I. Timp-1, -2 and -3 show coexpression with gelatinases $\mathrm{A}$ and $\mathrm{B}$ during mouse tooth morphogenesis. Eur J Oral Sci 1999;107: 121-30.

[15] Bourd-Boittin K, Septier D, Hall R, Goldberg M, Menashi S. Immunolocalization of enamelysin (matrix metalloproteinase-20) in the forming rat incisor. J Histochem Cytochem 2004;52: 437-45.

[16] Lu Y, Papagerakis P, Yamakoshi Y, Hu JC, Bartlett JD, Simmer JP. Functions of KLK4 and MMP-20 in dental enamel formation. Biol Chem 2008;389: 695-700.

[17] Nagano T, Kakegawa A, Yamakoshi Y, Tsuchiya S, Hu JC, Gomi K, Arai T, Bartlett JD, Simmer JP. Mmp-20 and Klk4 cleavage site preferences for amelogenin sequences. J Dent Res 2009;88: 823-8.

[18] Turk BE, Lee DH, Yamakoshi Y, Klingenhoff A, Reichenberger E, Wright JT, Simmer JP, Komisarof JA, Cantley LC, Bartlett JD. MMP-20 is predominately a toothspecific enzyme with a deep catalytic pocket that hydrolyzes type $\mathrm{V}$ collagen. Biochemistry 2006;45: 3863-74.

[19] Simmer JP, Hu JC. Expression, structure, and function of enamel proteinases. Connect Tissue Res 2002;43: 441-9.

[20] Bartlett JD, Simmer JP. Proteinases in developing dental enamel. Crit Rev Oral Biol Med 1999;10: 425-41.

[21] Toole BP. Emmprin (CD147), a cell surface regulator of matrix metalloproteinase production and function. Current topics in developmental biology 2003;54: 371-89.

[22] Gabison EE, Hoang-Xuan T, Mauviel A, Menashi S. EMMPRIN/CD147, an MMP modulator in cancer, development and tissue repair. Biochimie 2005;87: 361-8.

[23] Huet E, Gabison EE, Mourah S, Menashi S. Role of emmprin/CD147 in tissue remodeling. Connect Tissue Res 2008;49: 175-9.

[24] Attia M, Huet E, Delbe J, Ledoux D, Menashi S, Martelly I. Extracellular matrix metalloproteinase inducer (EMMPRIN/CD147) as a novel regulator of myogenic cell differentiation. Journal of cellular physiology 2011;226: 141-9.

[25] Kato N, Kosugi T, Sato W, Ishimoto T, Kojima H, Sato Y, Sakamoto K, Maruyama S, Yuzawa Y, Matsuo S, Kadomatsu K. Basigin/CD147 promotes renal fibrosis after unilateral ureteral obstruction. The American journal of pathology 2011;178: 572-9.

[26] Nabeshima K, Iwasaki H, Koga K, Hojo H, Suzumiya J, Kikuchi M. Emmprin (basigin/CD147): matrix metalloproteinase modulator and multifunctional cell recognition molecule that plays a critical role in cancer progression. Pathol Int 2006;56: 359-67.

[27] Liu L, Li C, Cai X, Xiang J, Cao Z, Dong W. The temporal expression and localization of extracellular matrix metalloproteinase inducer (EMMPRIN) during the development of periodontitis in an animal model. Journal of periodontal research 2010;45: 541-9.

[28] Gabison EE, Huet E, Baudouin C, Menashi S. Direct epithelial-stromal interaction in corneal wound healing: Role of EMMPRIN/CD147 in MMPs induction and beyond. Prog Retin Eye Res 2009;28: 19-33.

[29] Zhu X, Song Z, Zhang S, Nanda A, Li G. CD147: a Novel Modulator of Inflammatory and Immune Disorders. Curr Med Chem 2013.

[30] Si AI, Huang L, Xu J, Kumta SM, Wood D, Zheng MH. Expression and localization of extracellular matrix metalloproteinase inducer in giant cell tumor of bone. J Cell Biochem 2003;89: 1154-63.

[31] Konttinen YT, Li TF, Mandelin J, Liljestrom M, Sorsa T, Santavirta S, Virtanen I. Increased expression of extracellular matrix metalloproteinase inducer in rheumatoid synovium. Arthritis Rheum 2000;43: 275-80. 
[32] Yang Y, Lu N, Zhou J, Chen ZN, Zhu P. Cyclophilin A up-regulates MMP-9 expression and adhesion of monocytes/macrophages via CD147 signalling pathway in rheumatoid arthritis. Rheumatology (Oxford) 2008;47: 1299-310.

[33] Huet E, Vallee B, Szul D, Verrecchia F, Mourah S, Jester JV, Hoang-Xuan T, Menashi S, Gabison EE. Extracellular matrix metalloproteinase inducer/CD147 promotes myofibroblast differentiation by inducing alpha-smooth muscle actin expression and collagen gel contraction: implications in tissue remodeling. Faseb J 2008;22: 1144-54.

[34] Igakura T, Kadomatsu K, Kaname T, Muramatsu H, Fan QW, Miyauchi T, Toyama Y, Kuno N, Yuasa S, Takahashi M, Senda T, Taguchi O, Yamamura K, Arimura K, Muramatsu T. A null mutation in basigin, an immunoglobulin superfamily member, indicates its important roles in peri-implantation development and spermatogenesis. Dev Biol 1998;194: $152-65$.

[35] Igakura T, Kadomatsu K, Taguchi O, Muramatsu H, Kaname T, Miyauchi T, Yamamura K, Arimura K, Muramatsu T. Roles of basigin, a member of the immunoglobulin superfamily, in behavior as to an irritating odor, lymphocyte response, and blood-brain barrier. Biochemical and biophysical research communications 1996;224: 33-6.

[36] Muramatsu T, Miyauchi T. Basigin (CD147): a multifunctional transmembrane protein involved in reproduction, neural function, inflammation and tumor invasion. Histology and histopathology 2003;18: 981-7.

[37] Schwab W, Harada H, Goetz W, Nowicki M, Witt M, Kasper M, Barth K. Immunocytochemical and biochemical detection of EMMPRIN in the rat tooth germ: differentiation-dependent co-expression with MMPs and co-localization with caveolin-1 in membrane rafts of dental epithelial cells. Histochem Cell Biol 2007;128: 195-203.

[38] Xie M, Jiao T, Chen Y, Xu C, Li J, Jiang X, Zhang F. EMMPRIN (basigin/CD147) is involved in the morphogenesis of tooth germ in mouse molars. Histochemistry and cell biology 2010;133: 585-94.

[39] Yamakoshi Y, Hu JC, Fukae M, Yamakoshi F, Simmer JP. How do enamelysin and kallikrein 4 process the 32-kDa enamelin? Eur J Oral Sci 2006;114 Suppl 1: 45-51; discussion 93-5, 379-80.

[40] Yamakoshi Y, Richardson AS, Nunez SM, Yamakoshi F, Milkovich RN, Hu JC, Bartlett JD, Simmer JP. Enamel proteins and proteases in Mmp20 and Klk4 null and doublenull mice. Eur J Oral Sci 2011;119 Suppl 1: 206-16.

[41] Maurel DB, Jaffre C, Rochefort GY, Aveline PC, Boisseau N, Uzbekov R, Gosset D, Pichon C, Fazzalari NL, Pallu S, Benhamou CL. Low bone accrual is associated with osteocyte apoptosis in alcohol-induced osteopenia. Bone 2011;49: 543-52.

[42] Oliver WC PG. An improved technique for determining hardness and elastic modulus using load and displacement sensing indentation experiments. J Mat Res 1992;7: 1564-1583.

[43] Fong H, Foster BL, Sarikaya M, Somerman MJ. Structure and mechanical properties of Ank/Ank mutant mouse dental tissues--an animal model for studying periodontal regeneration. Arch Oral Biol 2009;54: 570-6.

[44] Cheng ZJ, Wang Q, Wang XM, Cui FZ, Ge J, Chen D, Tian LL. Enamel distribution, structure and mechanical alterations in col1-caPPR mice molar. Arch Oral Biol 2011;56: $1020-6$.

[45] Roche PC, Ryan RJ, McCormick DJ. Identification of hormone-binding regions of the luteinizing hormone/human corionic gonadotropin receptor using synthetic peptides. Endocrinology 1992;131: 268-274.

[46] Pfaffl MW. A new mathematical model for relative quantification in real-time RTPCR. Nucleic Acids Res 2001;29: e45.

[47] Nait Lechguer A, Kuchler-Bopp S, Hu B, Haikel Y, Lesot H. Vascularization of engineered teeth. J Dent Res 2008;87: 1138-43. 
[48] Ahmad N, Ruch JV. Comparison of growth and cell proliferation kinetics during mouse molar odontogenesis in vivo and in vitro. Cell Tissue Kinet 1987;20: 319-29.

[49] Birkedal-Hansen H. Role of matrix metalloproteinases in human periodontal diseases. J Periodontol 1993;64: 474-84.

[50] Bartlett JD, Beniash E, Lee DH, Smith CE. Decreased mineral content in MMP-20 null mouse enamel is prominent during the maturation stage. J Dent Res 2004;83: 909-13.

[51] Beniash E, Skobe Z, Bartlett JD. Formation of the dentino-enamel interface in enamelysin (MMP-20)-deficient mouse incisors. Eur J Oral Sci 2006;114 Suppl 1: 24-9; discussion 39-41, 379.

[52] Caterina JJ, Skobe Z, Shi J, Ding Y, Simmer JP, Birkedal-Hansen H, Bartlett JD. Enamelysin (matrix metalloproteinase 20)-deficient mice display an amelogenesis imperfecta phenotype. J Biol Chem 2002;277: 49598-604.

[53] Pugach MK, Suggs C, Li Y, Wright JT, Kulkarni AB, Bartlett JD, Gibson CW. M180 amelogenin processed by MMP20 is sufficient for decussating murine enamel. J Dent Res 2013;92: 1118-22.

[54] Bartlett JD, Skobe Z, Lee DH, Wright JT, Li Y, Kulkarni AB, Gibson CW. A developmental comparison of matrix metalloproteinase-20 and amelogenin null mouse enamel. Eur J Oral Sci 2006;114 Suppl 1: 18-23; discussion 39-41, 379. 


\section{Figure legends}

\section{FIG.1 Comparison of tooth germs in $\mathrm{KO}$ and WT mice}

\section{Panel A: Frontal section of the mandible at post-natal day 1.}

No difference in the molars germ morphology is observed between WT (+/+) and KO (-/-) mice, either at early bell stage (M2) or at late bell stage (M1). KO mice show no EMMPRIN immunostaining (d-f, j-l). In WT mice, the pre-ameloblasts and stratum intermedium are positive for EMMPRIN in M2 germ (a). The staining is particularly intense in the intercuspal curve (b) and decreases at the tip of the cusps (c). At a later stage (M1 germ), when cells actively secrete protein matrix, a light staining is visualized on ameloblast cell membrane (g). This staining progressively decreases from the intercuspal curve (h) to the tip of the cusps (i). By contrast, an intense staining of the odontoblasts is observed (h,i).

\section{PANEL B: Sagittal section of 3-month-old mandible}

No difference in the incisor morphology is observed between WT (+/+) and $\mathrm{KO}(-/-)$ mice. No EMMPRIN immunostaining is observed in $\mathrm{KO}$, whereas both ameloblasts and odontoblasts are labeled in WT.

p-Am: pre-ameloblast; p-Od: pre-odontoblast; Am: ameloblast; Od: odontoblast; Si: stratum intermedium; fm: forming matrix; D: dentin; pm-E: premature enamel.

\section{FIG.2. Micro-CT and nanoindentation analysis of mandibles of EMMPRIN KO adult} mice when compared with WT.

Mandibles collected from 3 month-old mice were analyzed using micro-CT and nanoindentation. Panel A: Reconstructed Micro-CT data show a mineralization delay of the developing incisor (I, white arrow) in KO mice. In WT mice, incisor mineralization (white arrow) is observed under M3 whereas in KO it is detected under M2. Panel B: Quantitative analysis of reconstructed mandible samples shows a significant lower enamel volume in 
EMMPRIN KO mice compared to WT $\left(6.94 .10^{8} \mu \mathrm{m}^{3}\right.$ versus $10.85 .10^{8} \mu \mathrm{m}^{3}$, respectively). A non-significant (NS) decrease is observed for total mineralized tissue volumes $\left(16.34 .10^{9} \mu \mathrm{m}^{3}\right.$ versus $17.96 .10^{9} \mu^{3}$, respectively). A $31 \%$ decrease in the ratio enamel volume / total mineralized tissue volume is seen in KO group. Enamel thickness, measured at M1, M2, incisor under M1 and incisor under M2 from $\mu \mathrm{CT}$ images, was significantly lower in EMMPRIN KO mice compared to WT $(0.139 \pm 0.006$ versus $0.117 \pm 0.006 \mathrm{~mm}$ at $\mathrm{M} 1, \mathrm{p}<$ $0.05 ; 0.140 \pm 0.003$ versus $0.124 \pm 0.001 \mathrm{~mm}$ at incisor under $\mathrm{M} 1, \mathrm{p}<0.001 ; 0.148 \pm 0.007$ versus $0.112 \pm 0.006 \mathrm{~mm}$ at $\mathrm{M} 2, \mathrm{p}<0.01$; and $0.142 \pm 0.002$ versus $0.127 \pm 0.002 \mathrm{~mm}$ at incisor under M2, p< 0.01; respectively). Panel C: Nanoindentation analysis of the incisor and the molar on frontal sections of the mandible performed at the level of M1 shows nonsignificant (NS) difference between KO and WT mice for enamel and dentin hardness and Young's modulus. e :enamel; dfp : dentin far from pulp; dmr: dentin middle region.

* indicates a statistically significant difference with the WT

FIG.3: Biochemical MMP evaluation of molar germs and developing incisor from EMMPRIN KO mice when compared with WT.

Panel A: Extracts from molar germs (M1 + M2) collected from WT and KO post-natal day 5 mice were analyzed for total MMP activity. A significant decrease is observed for KO $(19,130 \pm 769)$ compared to WT mice $(25,300 \pm 560)$. Similar results were found for lower incisor germs (soft part) collected in 3-month-old mice. Panel B: For MMP-3 mRNA expression, a $75 \%$ decrease is observed for $\mathrm{KO}$ mice when compared with WT by RT-PCR analysis of developing incisor extracts. For protein expression, a band is detected at about 50 $\mathrm{kDa}$ in both groups but with a $66 \%$ decrease in $\mathrm{KO}$ mice by Western blot analysis. MMP-3 activity is observed by casein zymography as a band at $50 \mathrm{kDa}$ (black arrow) in both $\mathrm{KO}$ and WT groups, but the band appears weaker in KO. A fainter band is also detectable underneath 
the major band in WT (white arrow), but not in KO mice. Recombinant MMP-3 is observed at 54 and $50 \mathrm{kDa}$. Panels C: For MMP-2 mRNA expression in developing incisor extracts, no detectable difference is observed for KO mice when compared with WT by qRT-PCR. Zymographic analysis shows no difference in MMP-2 activity between WT and KO. For both, 2 bands around $72 \mathrm{kDa}$ corresponding to proMMP- 2 and a band at $62 \mathrm{kDa}$ corresponding to the active MMP-2 are observed. Panel D: For MMP-9 mRNA expression, no difference is observed for KO mice when compared with WT by qRT-PCR. Zymographic analysis shows no difference in MMP-9 activity between WT and KO mice. For both, a band at $92 \mathrm{kDa}$ corresponding to pro-MMP-9 is detected.

* indicates a statistically significant difference with the WT group

FIG.4. MMP-20, and enamel matrix protein expression in tooth germs of EMMPRIN KO mice when compared with WT.

Panel A: For MMP-20 mRNA expression, a $35 \%$ decrease is observed for KO when compared with WT by RT-PCR analysis. For protein expression, several bands are detected with MMP-20 antibody between $45 \mathrm{kDa}$ and $15 \mathrm{kDa}$ in both samples but with about $50 \%$ decrease in $\mathrm{KO}$ mice. MMP-20 activity is observed by casein zymography as several bands detectable between 45 and $15 \mathrm{kDa}$ in both $\mathrm{KO}$ and WT groups, the strongest digestion band being observed at about $25 \mathrm{kDa}$. All the bands appear weaker in KO. Recombinant MMP-20 activity is observed at 28 and $18 \mathrm{kDa}$ (white arrows). Panel B: Western blot analysis shows with amelogenin (AMEL) antibody several bands extending from 27 to $17 \mathrm{kDa}$ for $\mathrm{WT}$ and $\mathrm{KO}$ mice, with enamelin antibody a small band at $130 \mathrm{kDa}$ and a larger band at about $60 \mathrm{kDa}$, and with ameloblastin antibody several bands extending from 65 to $17 \mathrm{kDa}$. No significant difference is observed between groups, but for ameloblastin some faint intermediate bands seen in WT mice are hardly detectable in KO. Western blot analysis with EMMPRIN 
antibody confirmed the absence of EMMPRIN in KO. Panel C: For MMP-20 expression, a staining of the matrix associated with the secreting pole of ameloblasts (am) is observed in WT (a, c). It increases progressively from the intercuspal curve (a) to the tip of the cusps (c) where forming dentin (fm) is seen. A faint staining is detected in KO mice (b-d) at the apical pole of ameloblasts located at the tip of the cusps (d). For AMEL expression, the staining is associated with secreting ameloblasts (am) and is particularly intense at the secretory pole. No difference is seen between WT (e,g) and KO (f,h) germs. am: ameloblast, od: odontoblast; fm: forming matrix. * indicates a statistically significant difference with the WT group.

\section{FIG. 5 Treatment of tooth germs with EMMPRIN SiRNA}

A: Mouse M1 germ sampled at E18 and cultured for 24 hours on semi-solid medium. B: RTPCR analysis of total RNA extraction from cultured M1 germs treated for 48 hours with EMMPRIN siRNA (lane 1: no siRNA; lane 2: siRNA $60 \mathrm{nM}$; lane 3: siRNA $120 \mathrm{nM}$; lane 4: scrambled siRNA). C: RT-PCR quantification with image $\mathrm{J}$ software showing that EMMPRIN expression is decreased at both siRNA concentrations $(63 \%$ and $90 \%$, respectively) leading to a significant decrease in MMP-20 (about $80 \%$ for both siRNA concentrations), and MMP-3 (50\% and $65 \%$, respectively) expression. No significant decrease is observed for MMP-2 and MMP-9.

* indicates a statistically significant difference with the "no siRNA" treatment group.

\section{FIG.6 Dentino-enamel junction observation of EMMPRIN KO and WT mice}

\section{Panel A: Laminin fluorescent staining in M2 germ from EMMPRIN KO and WT mice}

Laminin was analyzed by immunocytochemistry on M2 germs of new born mice to investigate basement membrane degradation. In WT mice, the staining at the level of basement membrane is faint and discontinuous $(\mathbf{A}, \mathbf{C})$, whereas in $\mathrm{KO}$ it is continuous (white 
arrows) (B, D). The staining is visible in the intercuspal zone (B) and at the tip of the cusps (D).

Panel B: SEM observation of 3 month-old mouse mandible sections.

In control, the DEJ (white arrows) is formed by well-intricate tissues in M1 (C) and in the underlying developing incisor (A). In contrast, these interactions between dentin and enamel are not visible in the EMMPRIN KO mice and a thick line separates both compartments $(\mathbf{B}$, D). This layer is observed as well in the molar (D) as in the developing underlying incisor (B). e: enamel. d: dentin.

\section{FIG.7. Recapitulative schema proposing the role of EMMPRIN in tooth formation}

At early bell stage, EMMPRIN is expressed by pre-ameloblast (p-Am) and may orchestrate basement membrane degradation (black line) to allow direct contact with pre-odontoblast (pOd), which is mandatory for the final cell differentiation. At secretory stage, both secreting ameloblasts (s-Am) and odontoblasts (Od) highly express EMMPRIN. This expression may enhance MMP-20 synthesis by ameloblasts allowing for early enamel maturation. At the enamel maturation stage, post-secretory ameloblasts (pos-Am) lose their EMMPRIN expression. The arrows indicate EMMPRIN expression by cells. The red line schematizes the time window where a direct effect of EMMPRIN is allowed by a direct cell contact. D: dentin; pD: predentin; pm-E: premature enamel; E: enamel.

\section{Supplementary FIG 1. EMMPRIN expression in the developing incisor of 3 month-old} mice

Immunostaining with EMMPRIN antibody on sagittal section of the mandible shows that the secretory ameloblasts, the stratum intermedium and odontoblasts are positive for EMMPRIN (A and B). By contrast, no staining is observed in the post-secretory ameloblast (C). Am: 
ameloblast; s-Am: secretory ameloblast; pos-Am: post-secretory ameloblast; Od: odontoblast; D: dentin; pD: predentin; pm-E: premature enamel; Si: stratum intermedium; fm: forming matrix.

Supplementary FIG.2 KLK-4 expression in tooth germs of EMMPRIN KO mice when compared with WT. For mRNA expression, a $33 \%$ increase is observed by qRT-PCR in KO mice. KLK-4 activity is hardly detectable by casein zymography (with $20 \mathrm{mM}$ EDTA in the incubation buffer to inhibit MMP activity). No activity is seen for recombinant MMP-20.

\section{Supplementary FIG.3 SEM observation of 3 month-old mouse mandible sections.}

At M1 level, no difference in the morphology of either the bone or the teeth is detected between WT and $\mathrm{KO}$ mice $(\mathbf{A}, \mathbf{B})$. Both dentin $(\mathbf{E}, \mathbf{F})$ and enamel appear normal and the enamel prisms are normally constituted $(\mathbf{C}, \mathbf{D})$. 
Figure1

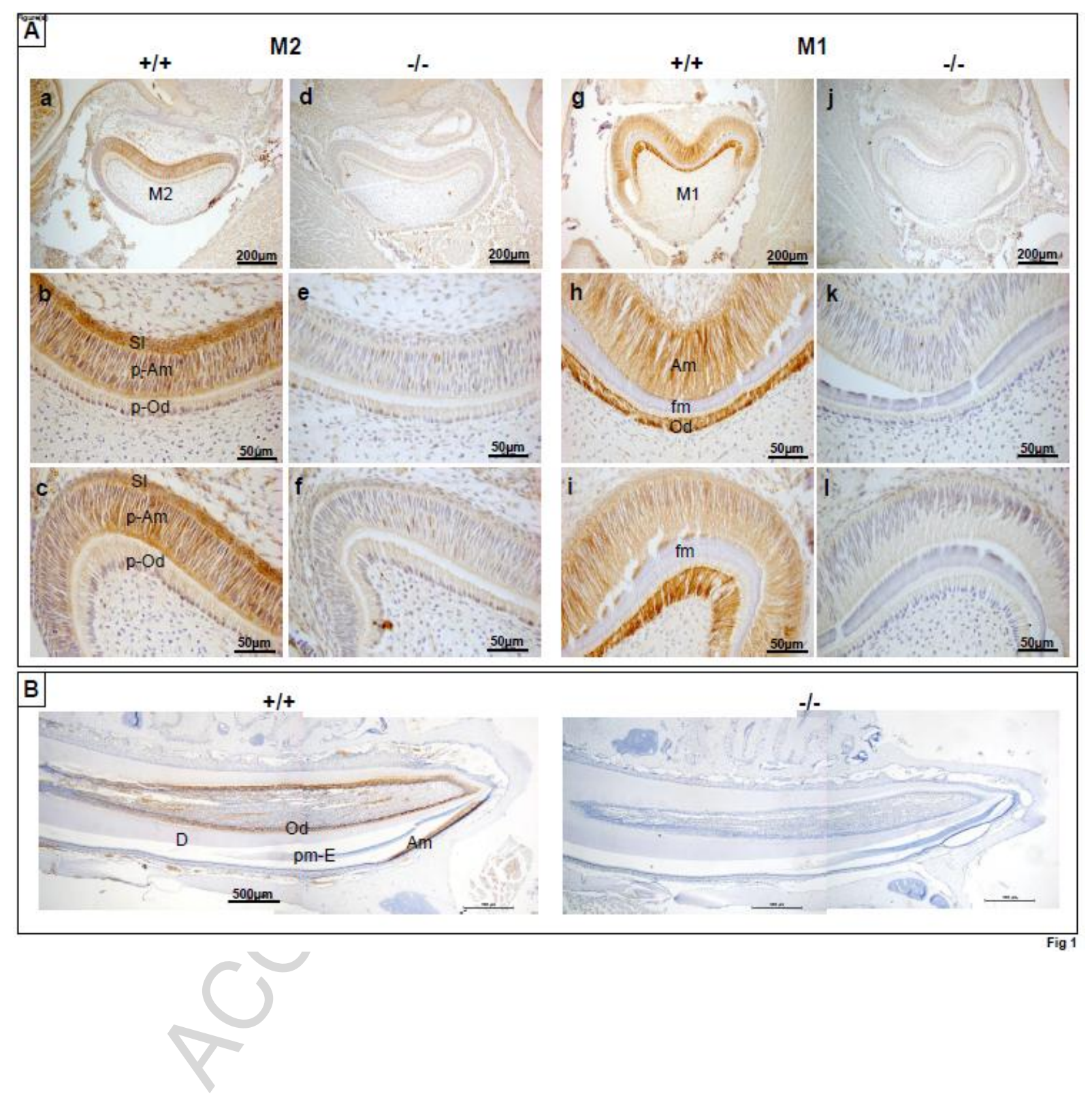


Figure2

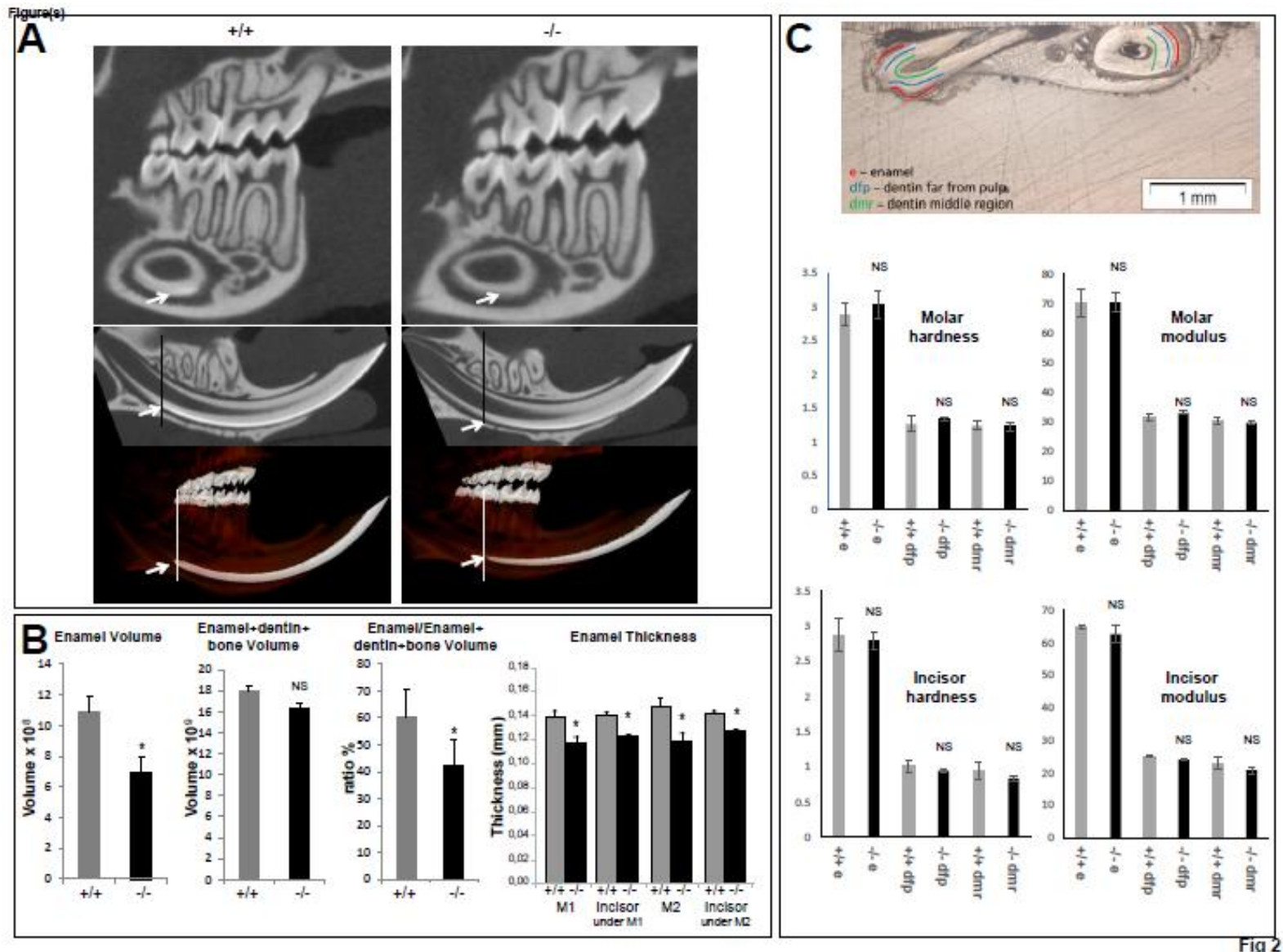


Figure3

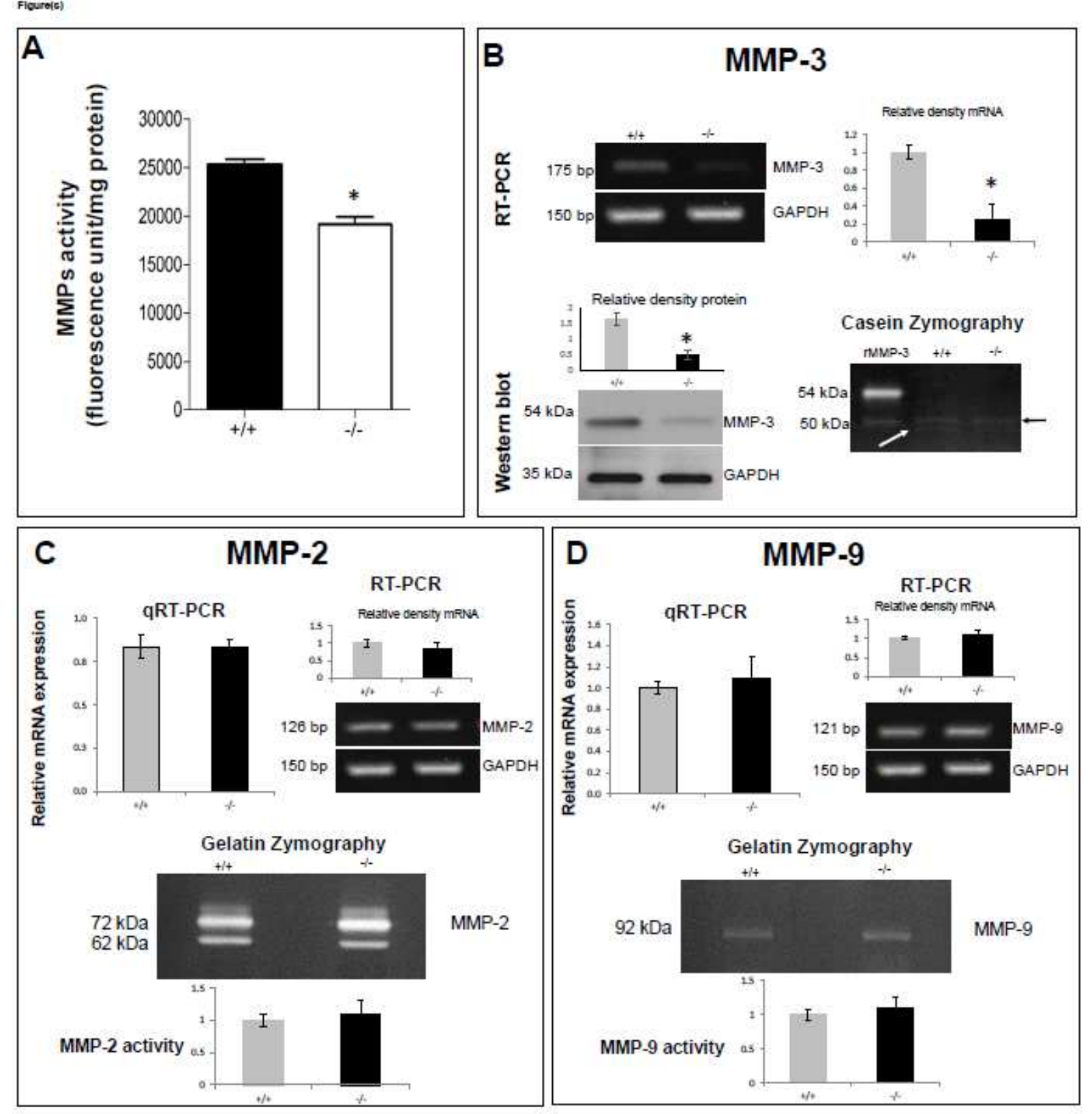

Fig 3 
Figure4

noment
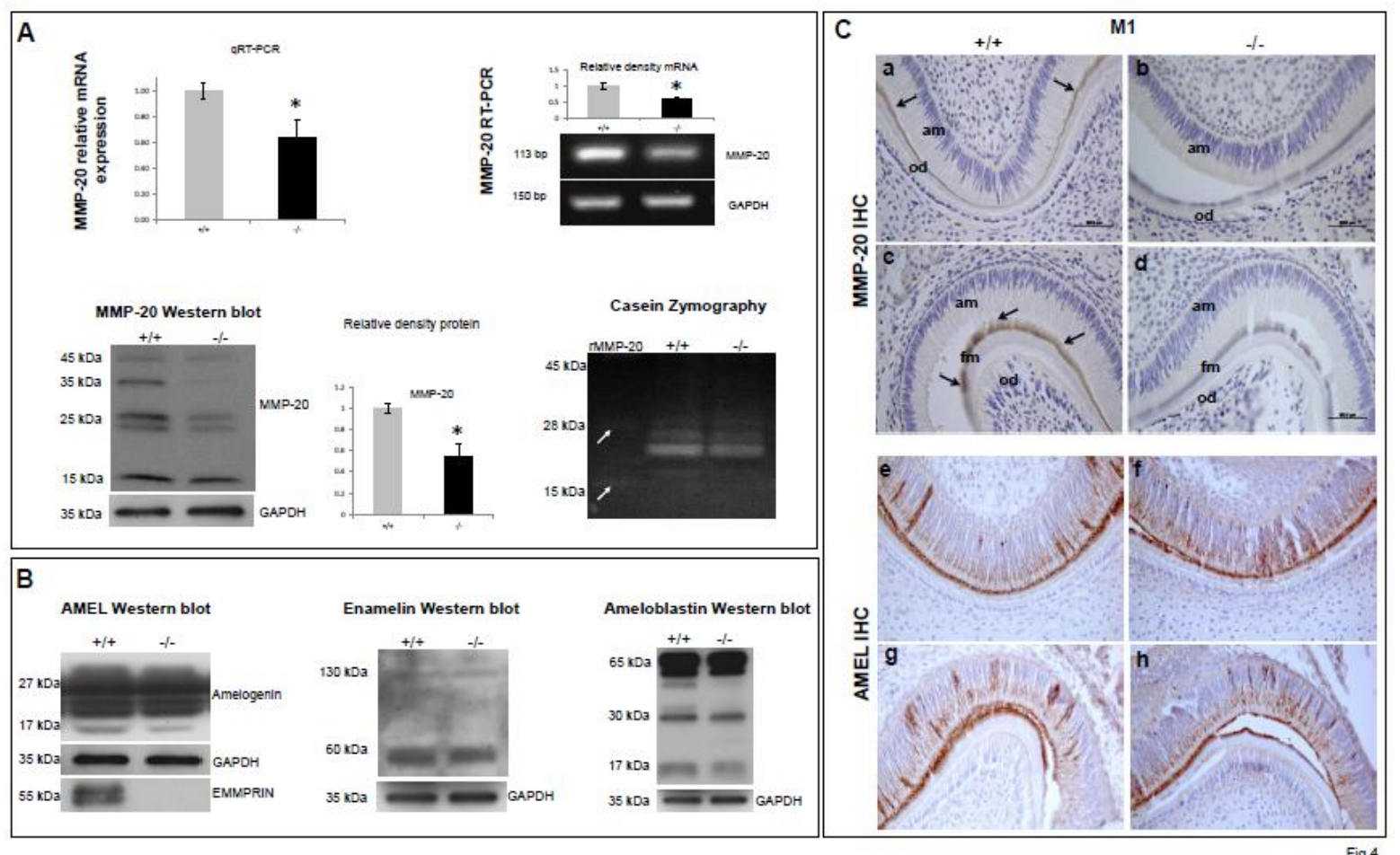
Figure 5
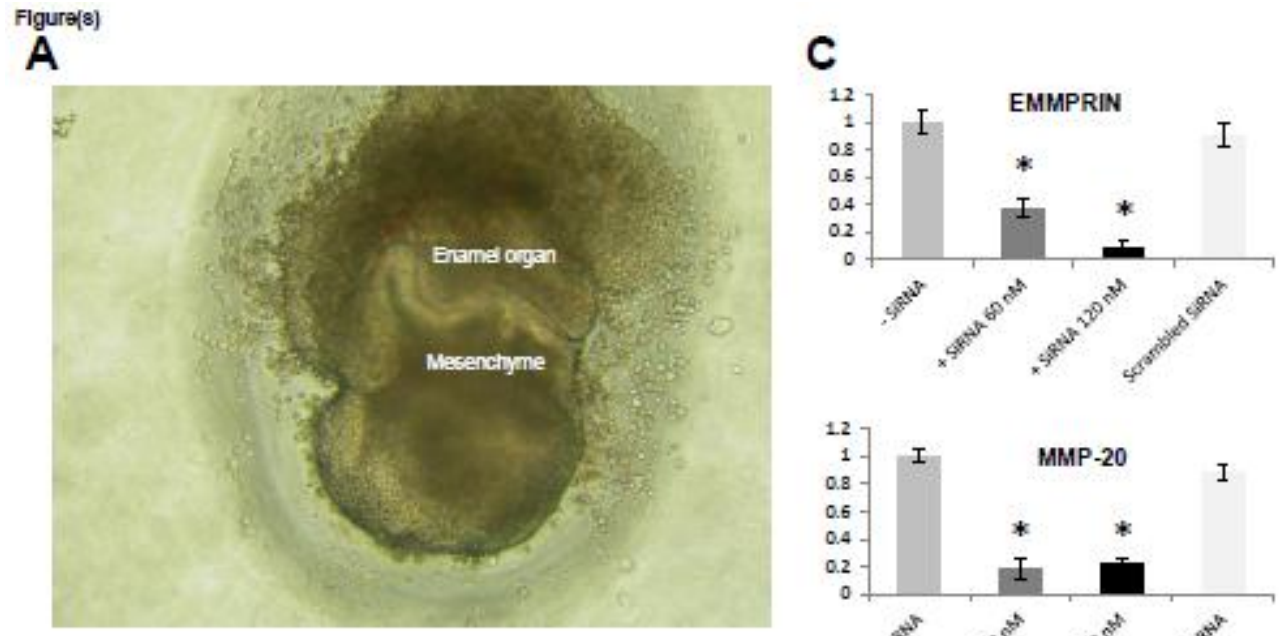

B
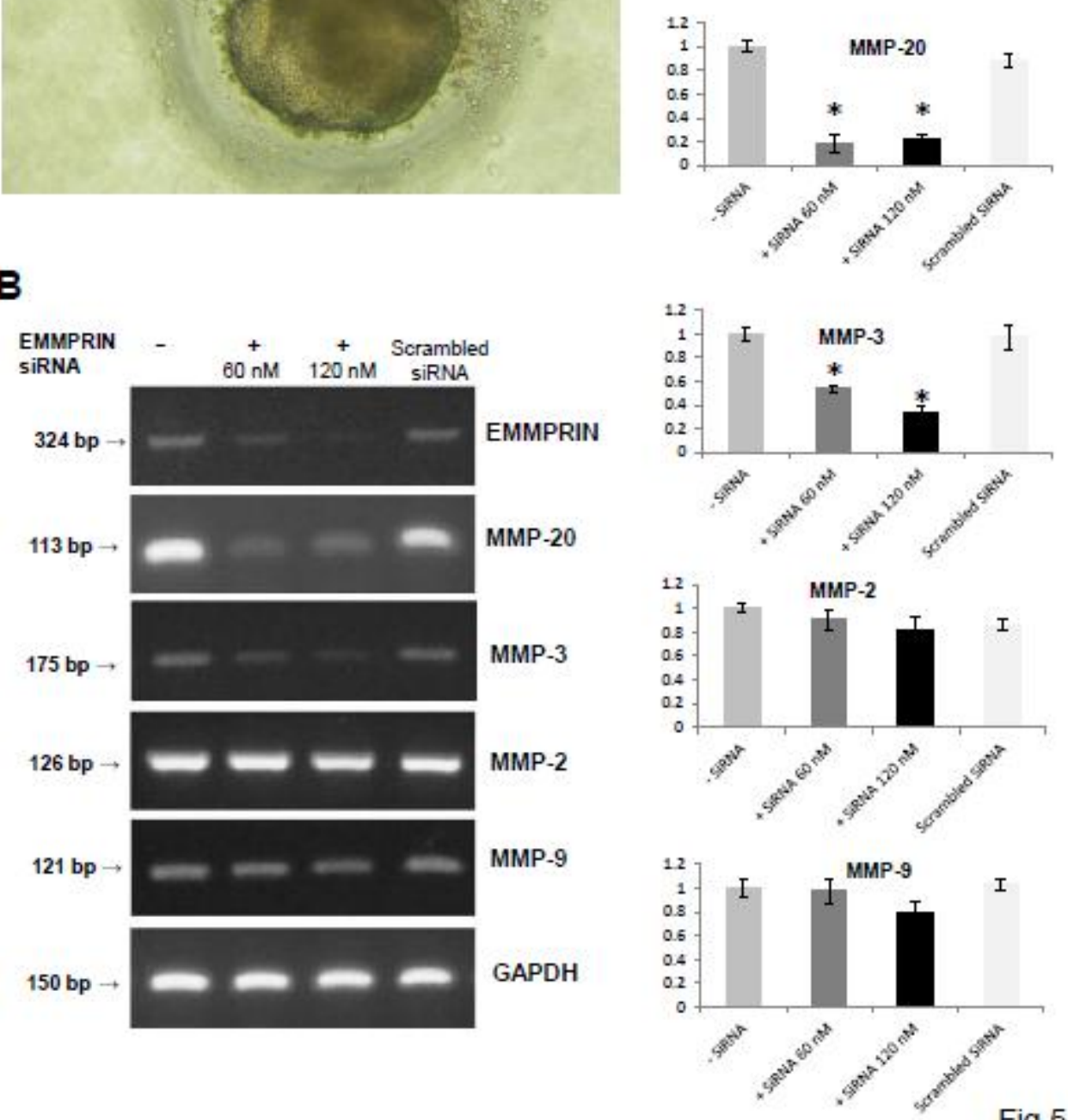

Fia 5 
Figure6

Figure(s)
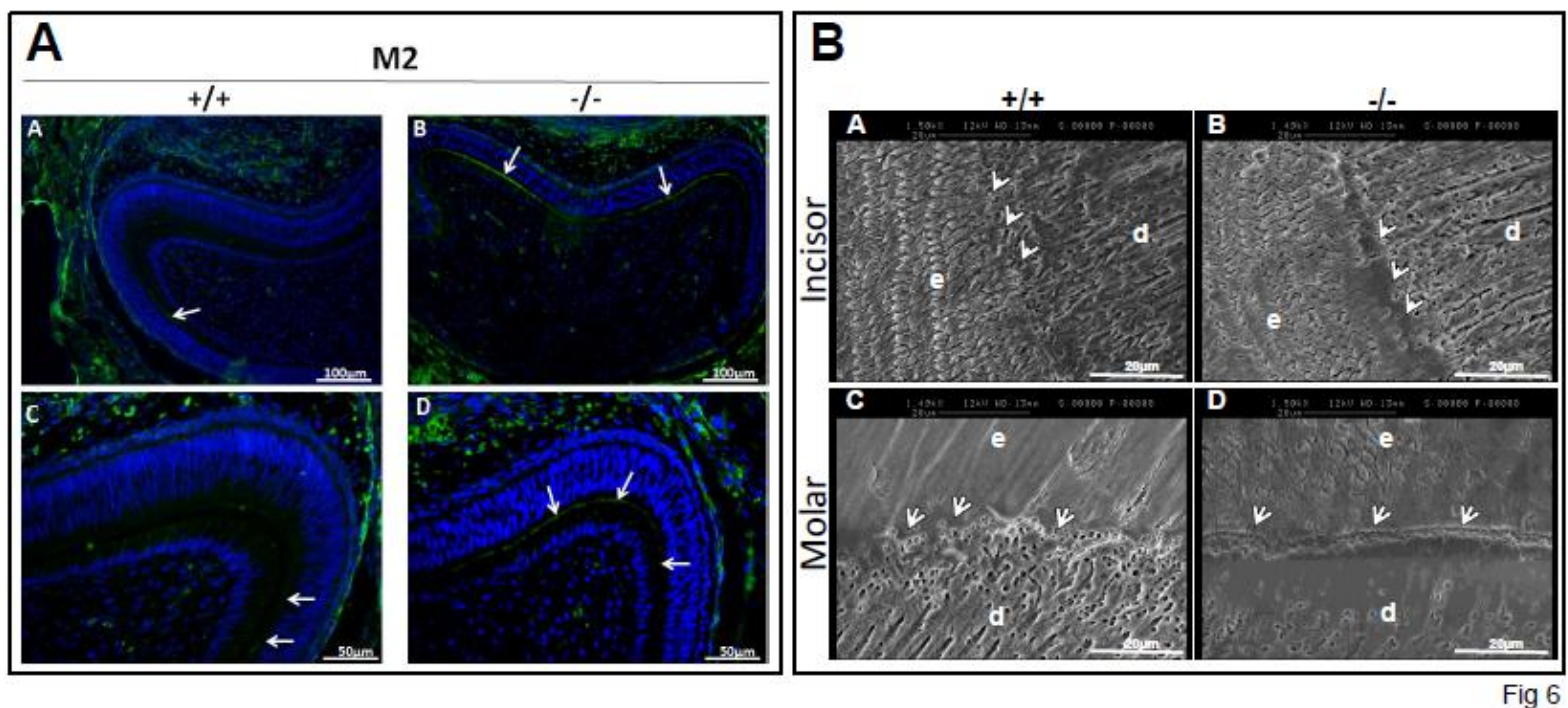
Figure7

Flgure(8)

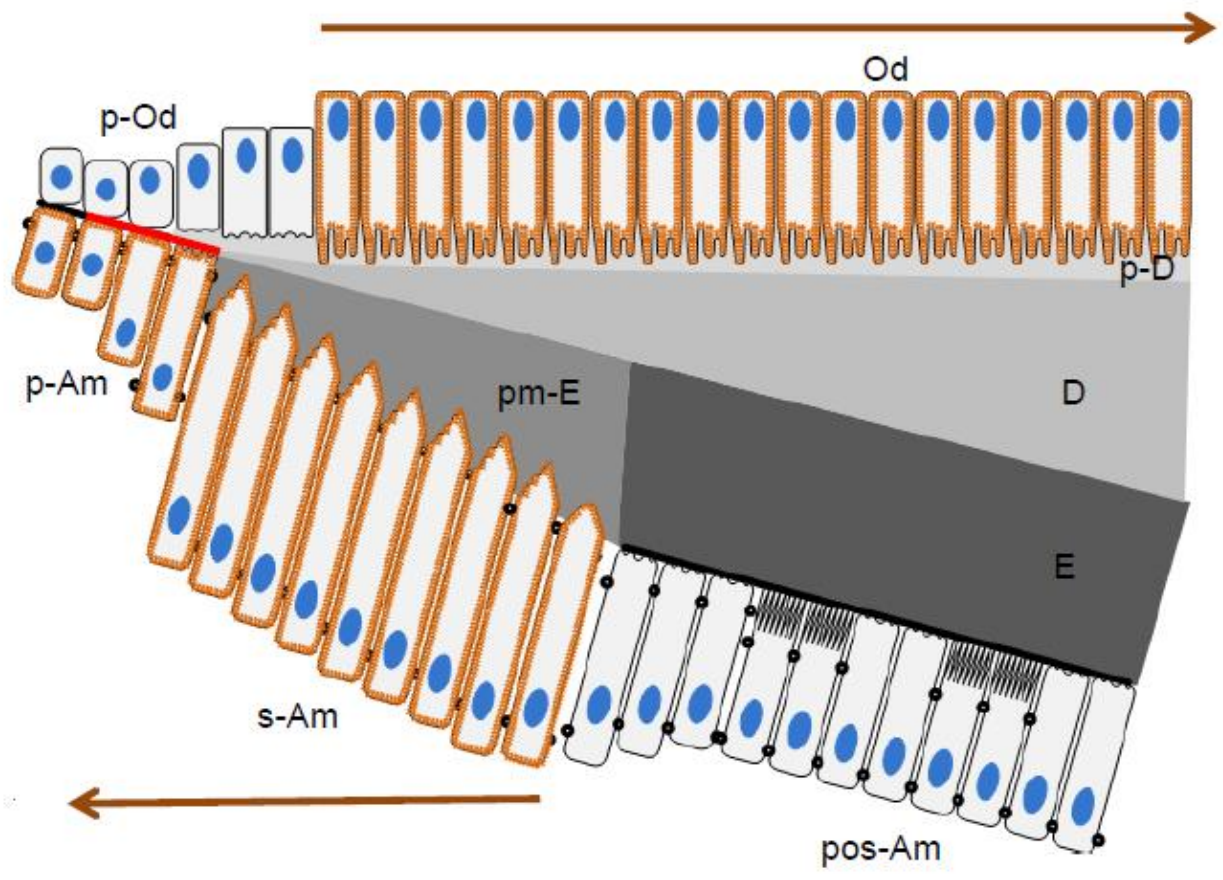

Fig 7 
$\checkmark$ Highlights

$\checkmark$ EMMPRIN, a mediator of epithelio-stromal interactions, is expressed during tooth development

$\checkmark$ MMP-3 and MMP-20 expressions are decreased in tooth germs of EMMPRIN KO mice

$\checkmark$ Basement membrane degradation is delayed in tooth germs of EMMPRIN KO mice

$\checkmark$ EMMPRIN KO mice has a delay in enamel formation well distinguishable in incisor

$\checkmark$ EMMPRIN deficiency results in decreased enamel volume and thickness but normal maturation. 